Water Management

Volume 167 Issue WM3

Modelling study on environmental

indicators in an estuary

Sun, Lin, Jiang, Li and Tao
Proceedings of the Institution of Civil Engineers

Water Management 167 March 2014 Issue WM3

Pages 141-151 http://dx.doi.org/10.1680/wama.12.00011

Paper 1200011

Received 10/01/2012

Published online 20/06/2013

Keywords: enviroment/mathematical modelling/pollution

ICE Publishing: All rights reserved

\title{
Modelling study on environmental indicators in an estuary
}

Jian Sun PhD

Lecturer, State Key Laboratory of Hydroscience and Engineering, Department of Hydraulic Engineering, Tsinghua University, Beijing, China Binliang Lin PhD

Professor, State Key Laboratory of Hydroscience and Engineering, Department of Hydraulic Engineering, Tsinghua University, Beijing, China; Professor, Cardiff School of Engineering, Cardiff, UK
Guoqiang Jiang PhD

Research Professor, South China Institute of Environmental Sciences, MEP, Guangzhou, China

Kaiming Li PhD

Research Professor, South China Institute of Environmental Sciences, MEP, Guangzhou, China

Jianhua Tao

Professor, School of Mechanical Engineering, Tianjin University, Tianjin, China

This paper reports on an investigation of the spatial and temporal variation of main environmental indicators in the Pearl River estuary using a numerical water quality model. An integrated field survey was undertaken in 2006 and 2007, and the data obtained were used to set up and verify the model. The water quality model was driven by a hydrodynamic model in which the monthly average freshwater discharges from eight major entrances were taken into account and the seaward boundary elevations were specified based on eight major tidal constituents. Two environmental indicators - dissolved inorganic nitrogen and chemical oxygen demand - were chosen as nutrient and pollution indicators, respectively, according to the actual pollution conditions. Both land-based sources (carried by the discharges) and air-based sources (wet and dry atmospheric depositions) were included in the water quality model and the processes of advection, diffusion and degradation were also modelled. The model predictions generally agreed well with the sampling data, and existing field and model results. The present contributions of the main sources were investigated and prospective scenarios of pollution reductions were predicted.

\section{Introduction}

Estuaries are the areas of interaction between freshwater from precipitation on land and salt water from open oceans (Nielsen, 2009). As it flows into the sea, the freshwater usually carries matter from the feeding river basins. Estuarine waters are characterised by strong gradients in environmental variables such as salinity, nutrients and organic matter, and this environmental heterogeneity constitutes essential conditions for maintaining species diversity (Lohrenz et al., 1990). However, with rapid industrialisation, population growth and intensified agricultural activities, more and more nutrients and organic pollutants are being dumped into the sea through estuaries. As a result, adverse effects on the ambient environment, such as water pollution and eutrophication, have become inevitable. Moreover, elevated nutrient concentrations in river waters often trigger high primary production and algal blooms in the river plume and adjacent estuarine and shelf waters (Dagg and Breed, 2003; Rabouille et al., 2008).

The Pearl River estuary (PRE) is a sub-tropical estuary located along the coast of the South China Sea (Figure 1). This is a complicated system with respect to both geometric and hydrodynamic properties. Over the past few decades, massive economic growth and urban development around this region have led to excessive release of waste into the estuary. Several field surveys have been conducted to investigate water quality in the estuary, and the results show that nutrients and organic pollutants are two of the major nutrient indicators, especially excess nitrogen overenrichment (Cai et al., 2004; Harrison et al., 2008; Huang et al., 2003; Xu et al., 2008; Yin and Harrison, 2008; Yin et al., 2000). As a result mainly of the high level of dissolved inorganic nitrogen (DIN) concentration, the water quality in the PRE and some adjacent areas is water quality level 5 (WQL 5, i.e. the worst polluted water (Chen et al., 2007)), according to the Chinese seawater quality standard (GB 3097-1997) in which water quality is divided into five WQLs. It is thus necessary to understand the process of spatial-temporal variation of environmental indicators in order to find a way to solve the environmental problems and develop new tools for building ecorestoration strategies in the PRE (Huang et al., 2003).

Numerical modelling, which can provide details of spatialtemporal variation of water quality indicators, is an effective supplement to field surveys. Chau and Jiang (2002, 2003) simulated the distribution and transport of chemical oxygen demand (COD) in the PRE with decay-type dynamics. Guan et al. (2001) designed an ecosystem-based water quality model to estimate the biochemical reaction, and then applied the model to predict the distributions of nutrients and dissolved oxygen. Simplified water quality models, such as decay-type models, are 


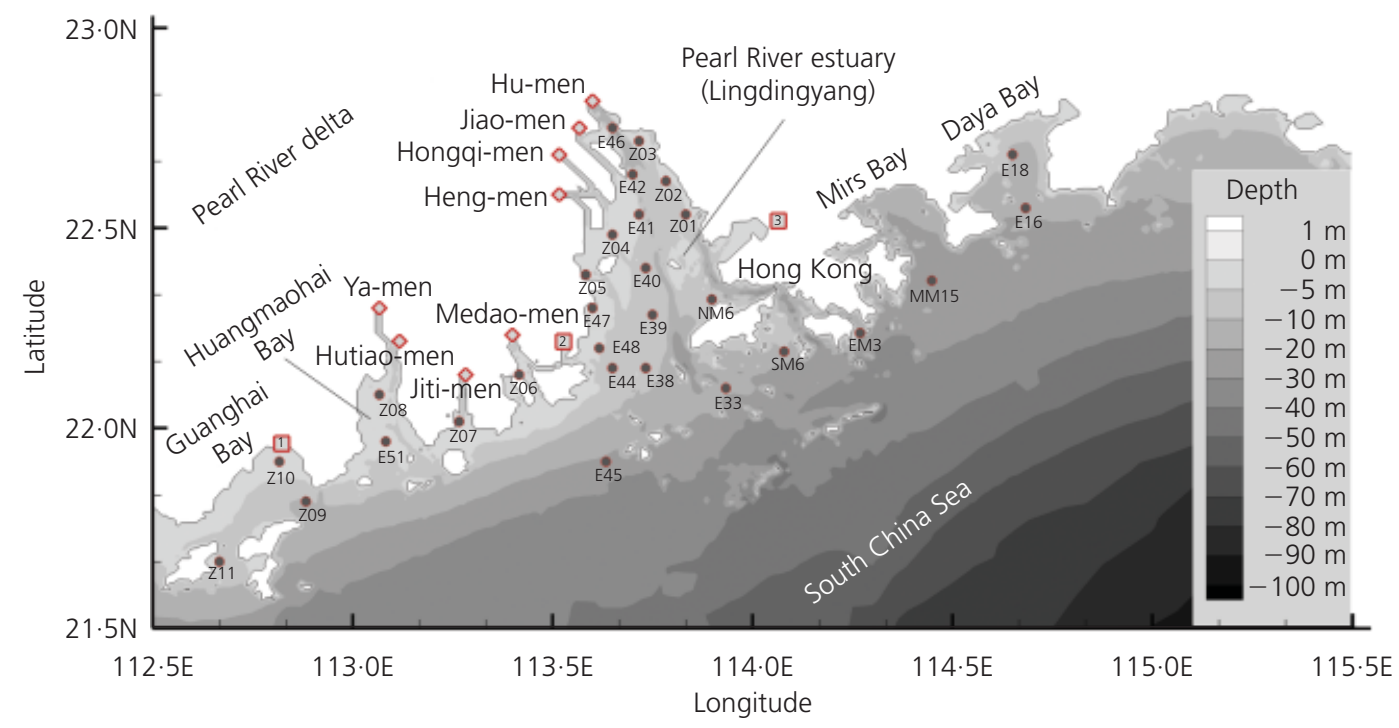

Figure 1. Topography of the Pearl River estuary and adjacent sea areas showing the eight major entrances, sampling stations (circles) and sluice-controlled rivers (squares: 1, Dalongdong; 2, Qianshanhe; 3, Shenzhenhe)

feasible in the study area for environmental indicators like DIN and COD because the dominant process is mixing (or dilution) and the biochemical reactions are secondary processes (Cai et al., 2004; Yin et al., 2000). To set up and verify this kind of model, adequate field data are still necessary. However, comprehensive investigations that involve pollutant contributions from various sources (such as major entrances and atmospheric depositions) to the distribution and variation of environmental indicators are seldom seen in previously reported studies, as are scenario predictions for planning pollution reductions in the PRE.

The main aim of the current study was thus to gain improved understanding of the distributions of environmental indicators and their seasonal variations in the PRE, and assess the effects of pollution reductions that could be implemented. A field survey in the PRE and adjacent coastal areas was conducted in 2006 and 2007. Assisted by these field exercises, a numerical water quality modelling study was undertaken. In view of the serious problems of eutrophication and industrial organic pollution, and according to the Chinese seawater quality standard (GB 3097-1997), DIN and COD were selected as nutrient indicators and pollution indicators respectively. As this study mainly concerned the horizontal distributions of these indicators, a horizontal twodimensional (2D) water quality model was employed with a firstorder decay equation being used to represent integrated functions of chemical and biological reactions.

Section 2 gives a brief introduction to the key geographic features of the PRE and its adjacent coastal areas. Section 3 presents some details of the field survey exercises and the numerical model. Section 4 details the model predictions and observed data, and the results are analysed in Section 5. Finally, the main conclusions from the study are outlined in Section 6.

\section{Study area}

This study is focused on the water quality in the PRE and adjacent coastal areas, within a square area defined by $21^{\circ} 30^{\prime}-$ $23^{\circ} 00^{\prime} \mathrm{N}$ and $112^{\circ} 30^{\prime}-115^{\circ} 00^{\prime} \mathrm{E}$ (Figure 1). The coastal line of the study area stretches from northeast to southwest, with the South China Sea located at the south side and the Pearl River delta at the north side. Hong Kong is located at the east bank of the PRE. The water depth is less than $20 \mathrm{~m}$ for most part of the estuary and bays. The total area of water surface in this domain is about $30000 \mathrm{~km}^{2}$.

The PRE is the biggest estuary of the Pearl River, which is the second largest river in China and the thirteenth largest river in the world in terms of mean annual water discharge (PRWRC, 1991). Located at about $22^{\circ} \mathrm{N}$ latitude, the Pearl River is a typical subtropical river (Rabouille et al., 2008). The total annual discharge is about $330 \times 10^{9} \mathrm{~m}^{3}$, according to historic data (Zhang et al., 2008). Passing through a complex river network in the Pearl River delta, freshwater discharge flows into the PRE and coastal areas mainly through eight major entrances - Hu-men, Jiao-men, Hongqi-men, Heng-men, Medao-men, Jiti-men, Hutiao-men and Ya-men from northeast to southwest respectively (Figure 1); the word 'men' means major entrance in Chinese. Apart from these major entrances, three rivers controlled by sluices (Dalongdong, Qianshanhe and Shenzhenhe) are located near Guanghai Bay, Medao-men and PRE respectively.

As a typical tidal river network, the hydrological processes in the 
Pearl River are rather complicated with regard to both the spatial and temporal distributions of the freshwater discharge. It is well known that there is a large seasonal variation in freshwater discharge, with about $80 \%$ of the total volume being discharged in the wet season and $20 \%$ in the dry season (Cai et al., 2004; Dong et al., 2004). The mean tidal range in the PRE varies between 0.8 and $1.7 \mathrm{~m}$ (Wong et al., 2003; Zhao, 1990). The tidal cycle is mainly a semi-diurnal mixed tidal regime with daily inequality in range and time between the highs and lows (Mao et al., 2004). M2 is the dominant tidal constituent, followed by K1, $\mathrm{O} 1$ and $\mathrm{S} 2$.

\section{Data and methods}

\subsection{Data acquisition}

An integrated field survey, which included field sampling in the study area, determination of pollution load and so on, had already been conducted as part of this study. In addition, historic data (e.g. freshwater discharge) were collected to support the modelling study.

\subsubsection{Sampling data}

Several cruise surveys were undertaken to investigate the horizontal distributions of environmental indicators, including salinity, DIN and COD, and their seasonal variations. As shown in Figure 1, 25 sampling stations were designated in the PRE and adjacent coastal areas. In order to cover the coastal area near Hong Kong, four of the routine stations (NM6, SM6, EM3, MM15) of the Environmental Protection Department of Hong Kong were also selected. The cruise surveys covered three typical periods: 5-16 July 2006 as the summer wet season; 17-24 September 2006 as the mean-flow season; 14-25 March 2007 as the spring dry season.

\subsubsection{Freshwater discharge data}

Freshwater discharge data were estimated based on records obtained from 1945 to 2004 by the Guangdong Research Institute of Water Research and Hydropower. Figure 2 shows the monthly average values of combined discharges of the two main channels. The discharge across these two rivers accounts for $84 \%$ of the

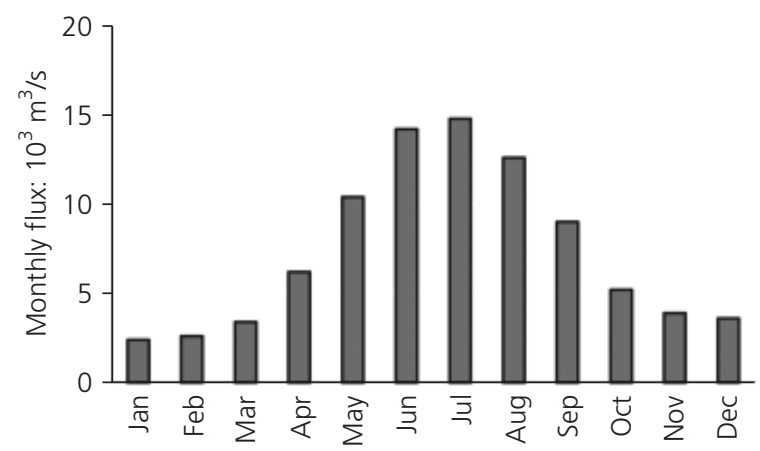

Figure 2. Monthly average values of combined discharges of two main rivers (Xijiang and Beijing rivers) total freshwater volume, which is consistent with previous studies (Cai et al., 2004; Kot and Hu, 1995; PRWRC, 1991; Rabouille et al., 2008; Zhang et al., 2008). Table 1 lists the annual discharges and proportion of freshwater contributions from the eight major entrances, which are also consistent with results from previous studies (Hou et al., 2004; Kot and Hu, 1995). It can be seen that, among the entrances, the discharge from Medao-men is the largest, followed by those from Hu-men and Jiao-men.

\subsubsection{Pollution load of DIN and COD}

Regarding coastal water quality, two types of pollution load are potentially important - the land-based load and the air-based load. Pollution loads were calculated based on the field surveys undertaken in 2006 and 2007. The annual land-based loads (including those from point sources $\left(M_{\mathrm{P}}\right)$ and those from nonpoint sources $\left(M_{\mathrm{N}}\right)$ ) from the eight major entrances are shown in Figure 3. It can be seen that Hu-men, Medao-men and Jiao-men are the three largest contributors of DIN and COD, which is related to the large freshwater discharge from these three

\begin{tabular}{lcr} 
Entrance & $\begin{array}{c}\text { Annual discharge: } \\
10^{9} \mathrm{~m}^{3}\end{array}$ & Proportion: \\
\hline Hu-men & 60.31 & 18.50 \\
Jiao-men & 56.50 & $17 \cdot 33$ \\
Hongqi-men & 20.88 & 6.41 \\
Heng-men & 36.58 & 11.22 \\
Medao-men & 92.24 & 28.30 \\
Jiti-men & 19.69 & 6.04 \\
Hutiao-men & 20.21 & $6 \cdot 20$ \\
Ya-men & 19.57 & 6.00 \\
Total & 325.98 & 100.00
\end{tabular}

Table 1. Annual discharges of eight major entrances to the Pearl River estuary

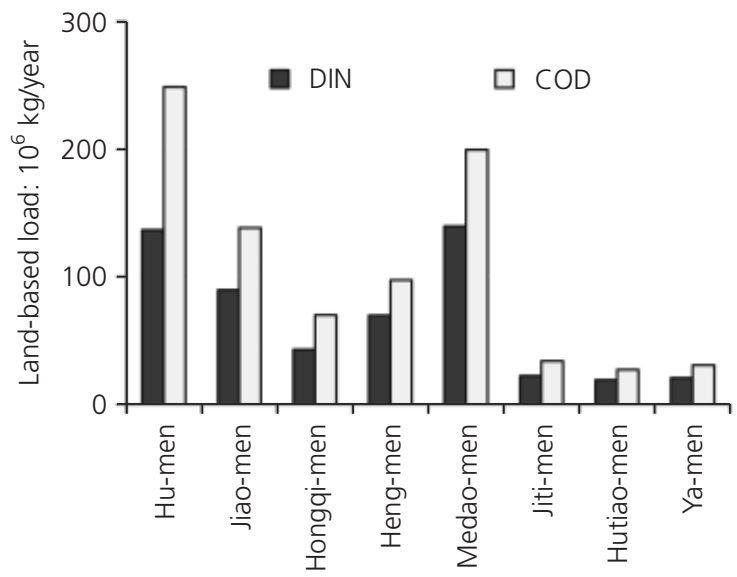

Figure 3. Annual land-based load of COD and DIN from the major entrances 
entrances. The temporal fluxes $(F)$ of DIN and COD loads are given as

1. $F(t)=\frac{M_{\mathrm{P}}}{T}+\frac{M_{\mathrm{N}} Q_{\text {River }}(t)}{\int_{0}^{T} Q_{\text {River }}(t) \mathrm{d} t}$

where $T$ is the time period ( 1 year) and $Q_{\text {River }}(t)$ is the temporal river freshwater discharge. In this study, the monthly average DIN and COD loads were used together with the monthly average freshwater discharges.

Wet and dry atmospheric depositions were measured to estimate the air-based loads (Fan et al., 2010; He et al., 2008). The monthly variation of the wet and dry atmospheric depositions of DIN shown in Figure 4 indicates that atmospheric deposition is generally more intensive in the wet season than in the dry season. An exception is seen in July, which is thought to be related to this specific year of measurements; the deposition value for August was used for the wet season in the simulation thereafter.

\subsection{Model description}

\subsubsection{Hydrodynamic model}

A depth-integrated 2D numerical model was used to calculate the water level and velocity distributions. In this model, the study domain was discretised in a space-staggered grid, with the water elevation located at the centre of a grid cell and the flux at the side of the cell. The alternating direction implicit finite-difference scheme was used to solve the governing equations (Lin and Falconer, 1995). This scheme is essentially second-order accurate both in time and space with no stability constraints owing to the time-centred implicit characteristics. This hydrodynamic model has been successfully used in Chinese coastal areas (Nie and Tao, 2009a, 2009b; Sun and Tao, 2006; Sun et al., 2009; Tao et al., 2001) and is able to deal with complex topography, such as various tidal flats (Sun and Tao, 2010).

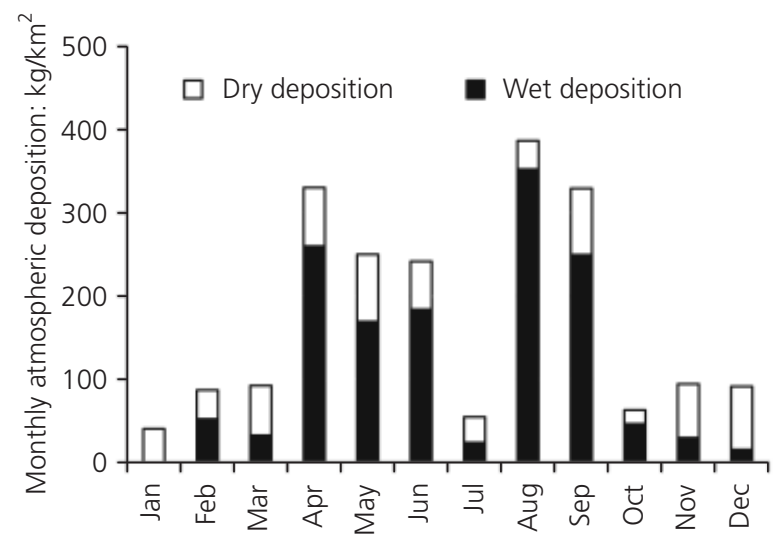

Figure 4. Monthly variation of wet and dry atmospheric depositions of DIN
At the seaward boundary, the temporal variation of water elevation was specified, which was calculated based on constants obtained from harmonic analysis. Eight tidal constituents were taken into account, including four main constituents (M2, S2, K1 and $\mathrm{O} 1$ ) and four minor constituents (N2, P2, K2 and Q2). The harmonic constants are given by a global tidal model named TPXO6.2 (Egbert and Erofeeva, 2002). At the riverward boundary, the eight major entrances were treated as flow boundaries, while other discharges are small and regarded as point source inputs.

\subsubsection{Water quality model}

The following solute transport equation is used in the water quality model

$$
\begin{aligned}
& \frac{\partial(H \phi)}{\partial t}+\frac{\partial(H U \phi)}{\partial x}+\frac{\partial(H V \phi)}{\partial y}= \\
& \frac{\partial}{\partial x}\left(H D_{x} \frac{\partial \phi}{\partial x}\right)+\frac{\partial}{\partial y}\left(H D_{y} \frac{\partial \phi}{\partial y}\right) \\
& +q_{\text {River }} \phi_{\text {River }}+\Phi_{\text {Air }}-\alpha H \phi
\end{aligned}
$$

where $\phi$ is the concentration of environmental indicators (salinity, DIN or COD), $H$ is the total depth, $U$ and $V$ are the velocity components in the $x$ and $y$ directions, respectively, $D_{x}$ and $D_{y}$ are dispersion-diffusion coefficients, $q_{\text {River }}$ and $\phi_{\text {River }}$ are the river discharge per unit area and the input concentration, respectively, $\Phi_{\text {Air }}$ is the (wet and dry) atmospheric deposition, and $\alpha$ is the first-order decay coefficient (per day) representing integrated functions of chemical and biological reactions.

It can be seen from Equation 2 that both land-based sources and air-based sources were taken into account, as were the processes of advection, dispersion and decay. The seawater boundary conditions of water quality were specified according to observed properties

a the boundary line where the water column is deeper than $50 \mathrm{~m}$, concentrations of COD and DIN are set to zero and the salinity level is set to be 35

at other boundary positions, a zero-gradient of indicators is used.

Equation 2 was discretised and solved with a space step of $1 \mathrm{~km}$ and a time step of $30 \mathrm{~s}$. The total simulation period was 2 years, from 1 January 2006 to 31 December 2007, and the spin-up time was 2 months.

\section{Verification}

\subsection{Hydrodynamic model}

The hydrodynamic model was verified against the data from this survey and previous studies. Figure 5 shows comparisons of water 


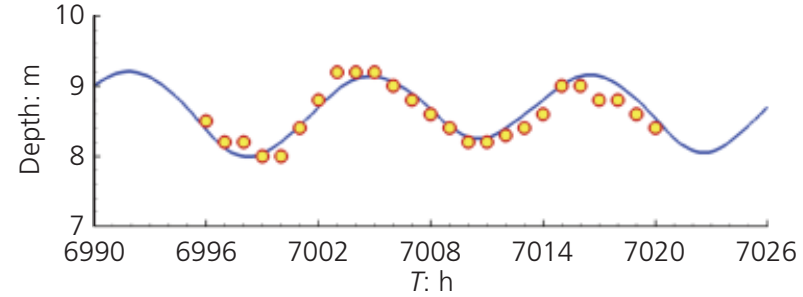

(a)

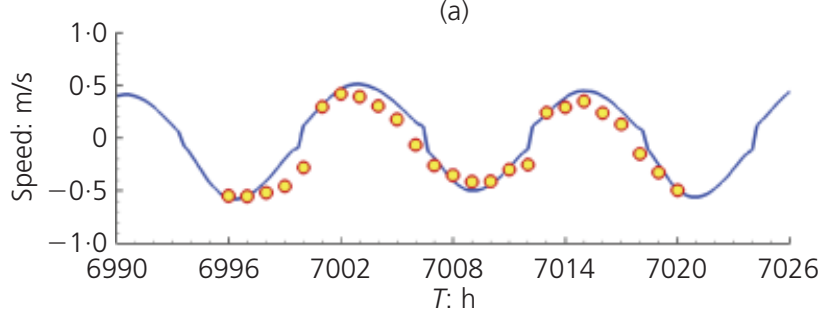

(b)

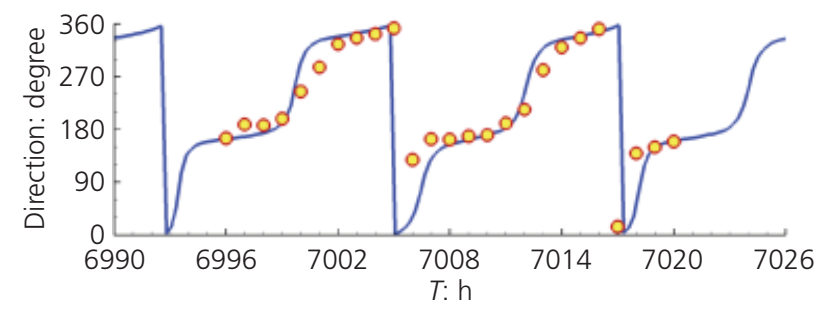

(c)

Figure 5. Comparison of predicted (curves) and measured (circles) hydrodynamic factors for station E38, 12:00 19 October 2006 to 12:00 20 October 2006

depth and velocity variations between the model prediction and field survey at station E38 from 12:00 19 October 2006 to 12:00 20 October 2006. It can be seen that the model-predicted water depth and velocity distributions agree closely with the data measured in real flows. Figure 6 shows a comparison of predicted and measured tidal harmonic constants; the measured data were obtained from Admiralty tidal tables (HoN, 1990) and a survey carried out by Mao et al. (2004) during both dry and wet seasons in 1998. The close agreement between the model-predicted and measured tidal amplitudes indicates the reliability of the model prediction for long-term hydrodynamic processes.

\subsection{Water quality model}

The water quality model consists of two main sub-models: the advection-diffusion model and the source model. The advectiondiffusion model was first verified against the salinity distribution, for which the source term was zero. The two environmental indicators (DIN and COD) were then predicted. The modelpredicted distributions of salinity level and DIN and COD concentrations in three typical seasons are shown in Figure 7. The salinity level shows a decreasing trend from the outer estuary to the inner estuary, while a generally increasing trend can be seen for DIN and COD. These trends show that the DIN and COD carried by freshwater from rivers are diluted by seawater.

Comparisons with measurements are shown in Figure 8. The

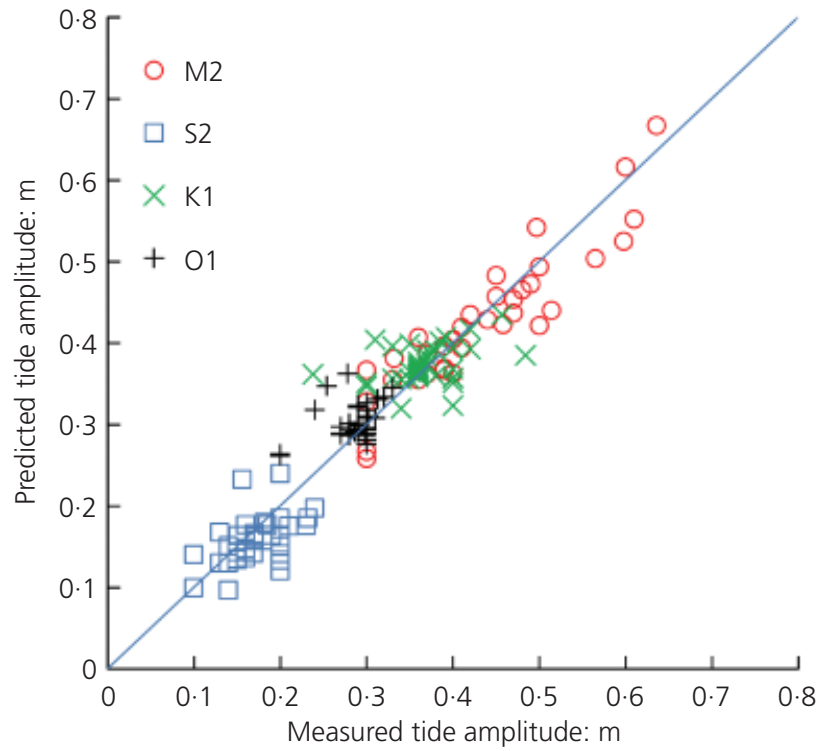

Figure 6. Comparison of predicted and measured tide amplitudes; measured data from HoN (1990) and Mao et al. (2004)

predicted salinity level and DIN and COD concentrations generally agree well with the observed values, which is also positively supported by previous field observations (Dai et al., 2006; Qiu et al., 2010; Yin et al., 2000; Zhang et al., 1999).

The agreement between the predicted COD and field data is not as close as that of DIN. This is thought to be related to the low level of COD concentration in this area. In such conditions, the complex chemical-biological reaction is important, to some degree, for the variation of COD concentration. This is also supported by the statistical results that DIN has a closer relationship with salinity than COD. However, the major environmental factor is DIN rather than COD because the DIN is at such a high level and the COD at a low level. The prediction accuracy is, however, appropriate for COD with the simple decay-type model as the main purpose of this study was to provide information to local environmental managers to help them plan for integrated pollution reduction.

\section{Results and discussion}

\subsection{Sensitivity analysis of decay coefficients}

The decay process is an important factor influencing the distribution of environmental indicators, together with the dilution process. Considering the range of measured decay coefficients, a sensitivity analysis was undertaken. Figure 9 shows that the error in COD reached the minimum value when the decay coefficient was between $0 \cdot 05 /$ day and $0 \cdot 10 /$ day. This range is approximately at the mean level of the measured decay rates. Wang et al. (2004) estimated the mean decay coefficient to be about 0.052 /day with in situ incubation experiments in Bohai Bay, which is close to the present result. Chau and Jiang (2003) set up their water quality model with a decay coefficient of $0 \cdot 25$ /day, which is thought to be 


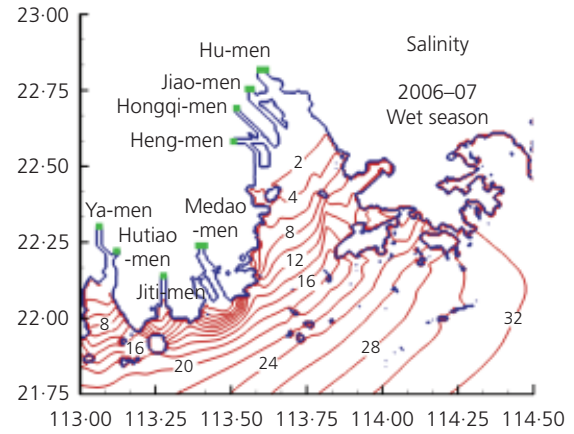

(a)

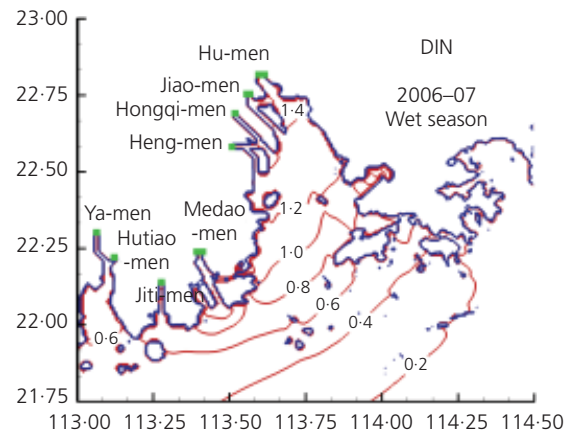

(d)

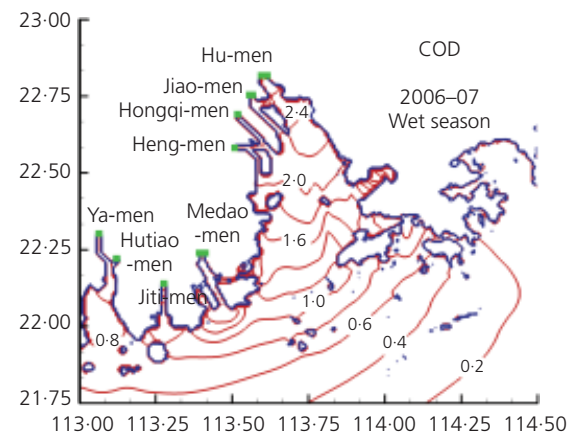

(g)

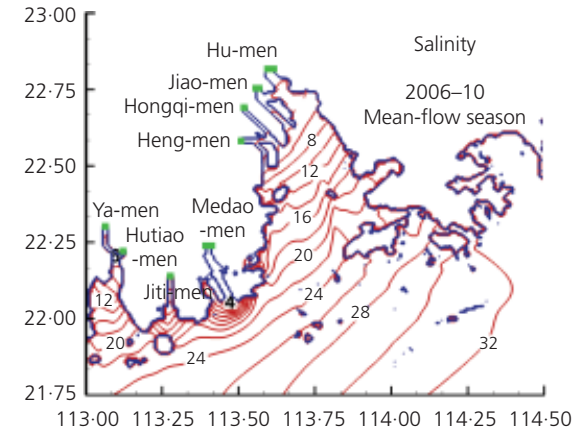

(b)

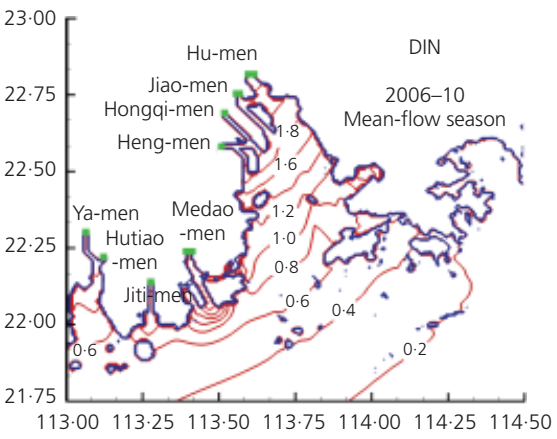

(e)

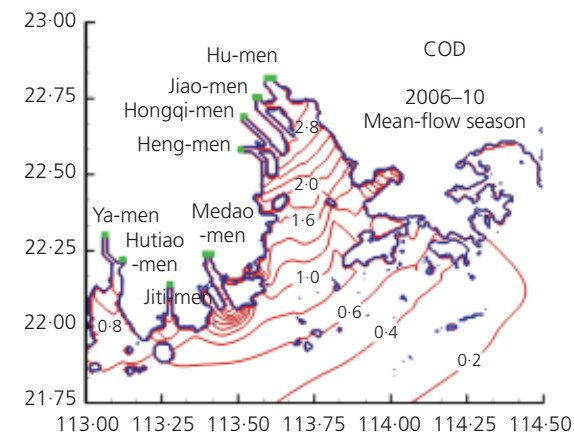

(h)

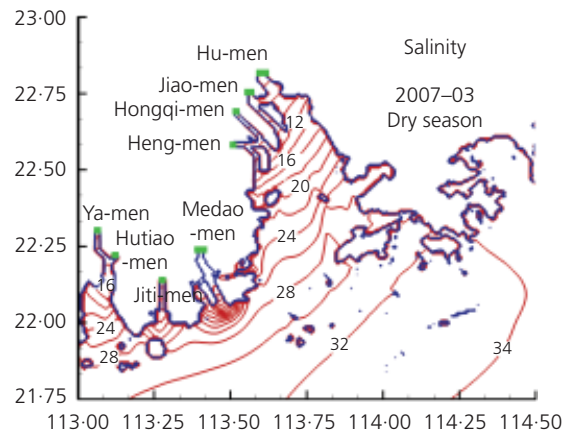

(c)

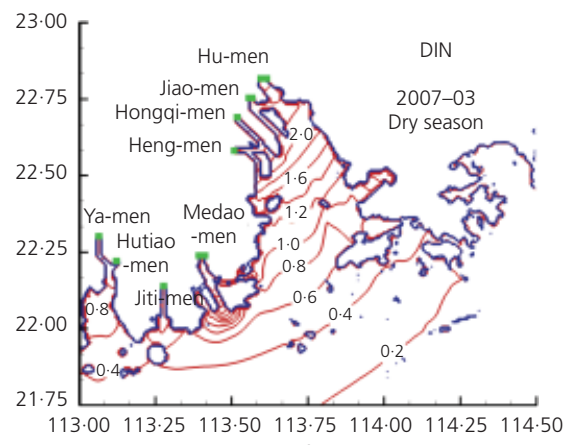

(f)

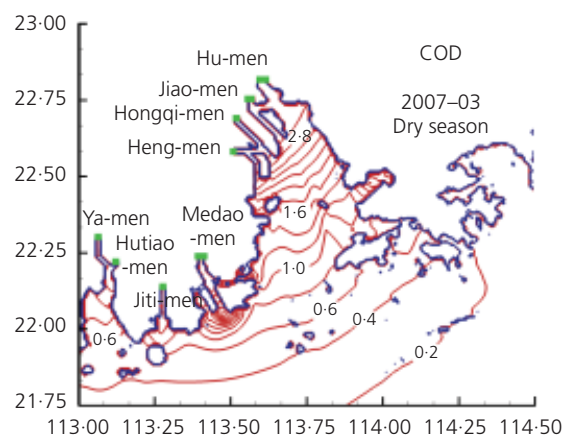

(i)

Figure 7. Horizontal distribution of model-predicted salinity level and dissolved inorganic nitrogen (DIN) (mg/l) and chemical oxygen demand (COD) concentrations ( $\mathrm{mg} / \mathrm{l})$. The contour is plotted by the monthly average values

rather high. For DIN, the error is maintained at the same level (i.e. it is not sensitive to the decay coefficient). This is because the magnitude of the DIN decay coefficient is rather small (about one fifth of the value of the COD decay coefficient) and so the DIN can be regarded as conservative. In other words, DIN will be flushed out of the inner estuary before it has a chance to decay substantially. It should be noted that the value of the decay coefficient may have seasonal variations, but this cannot be confirmed by the present study owing to a lack of more extensive data. The use of a constant decay coefficient can be considered acceptable given the generally good agreement shown in Figure 9.

\subsection{Source reconciliation}

The actual distributions of DIN and COD concentrations in the PRE are influenced by all of the input pollution sources discharging into the estuary. It is important to identify the independent contributions of individual sources to enable reliable assessment of the environmental state and regional environmental management planning for future improvements.

In this study, the contribution of a specified source to the spatialtemporal distribution of a water quality indicator is represented by the single source response (SSR) relationship (i.e. the concentration distribution under the effect of a single pollution source). This method can be used to assess the contribution of every source. Figure 10 shows the predicted SSR distributions of DIN concentrations, which are related to atmospheric deposition and the DIN loads from major entrances in the wet season.

Figure 10(a) indicates that the DIN concentration due to 

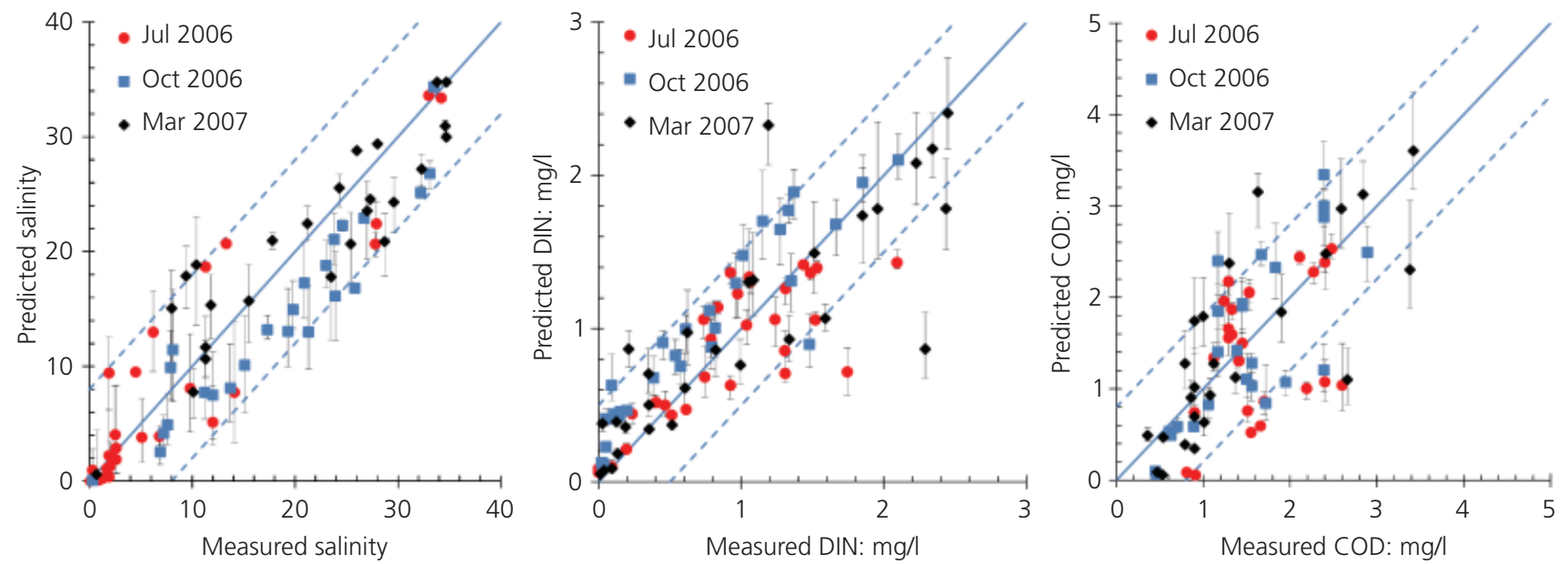

Figure 8. Comparison of predicted and measured dissolved inorganic nitrogen (DIN) and chemical oxygen demand (COD) concentrations. Error bars are used to denote the variation range due to the tidal fluctuations
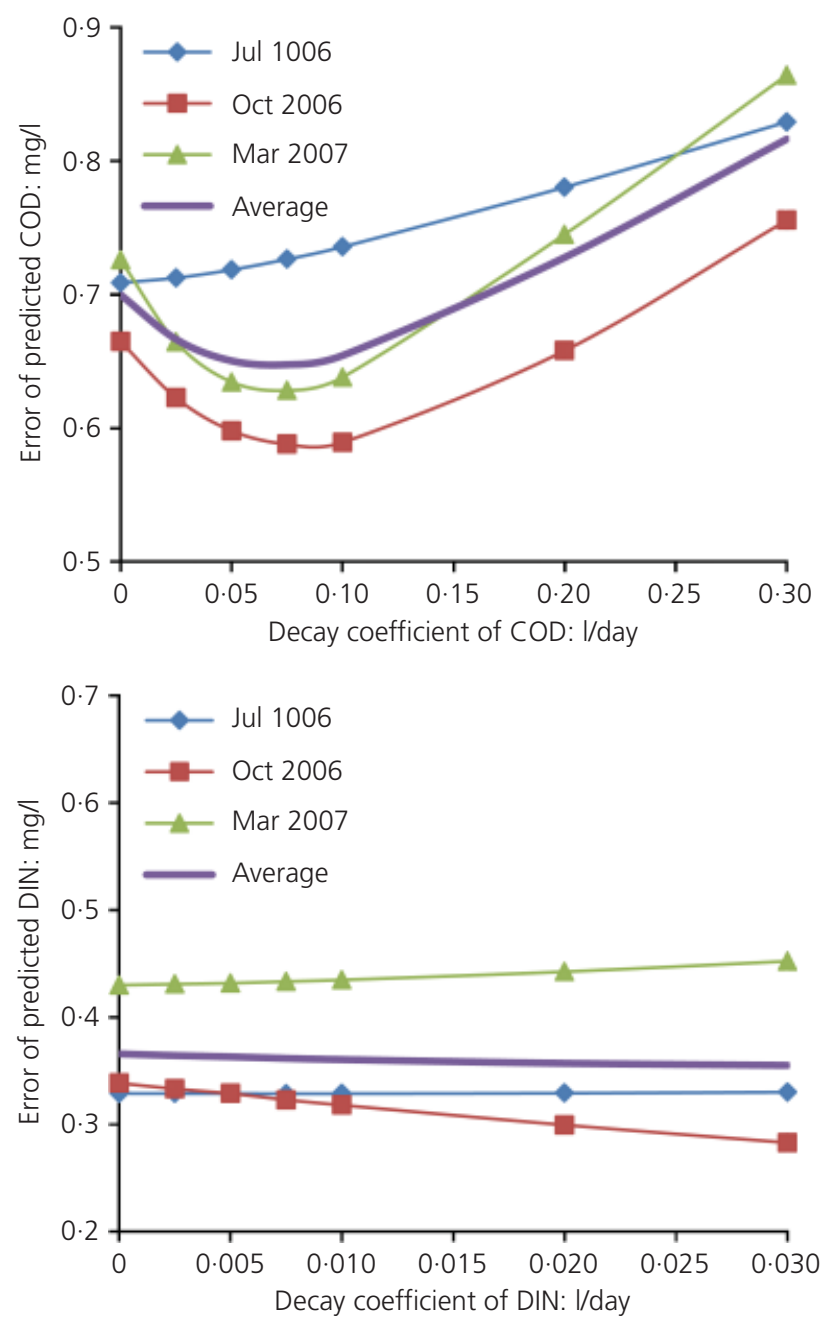

Figure 9. Sensitivity analysis of decay coefficients

atmospheric deposition is higher in the southern PRE than in the northern region and outer sea. In the northern region, the DIN level is relatively low because material from atmospheric deposition has been diluted by a large amount of freshwater, while in the outer sea the water depth is greater and thus the concentration is lower. In the southern part of the PRE the maximum concentration is about $0.030 \mathrm{mg} / \mathrm{l}$. Compared with the real DIN concentration in the PRE, which is about $1.2 \mathrm{mg} / \mathrm{l}$, as shown in Figure $7(\mathrm{~d})$, the contribution due to atmospheric deposition is very small (i.e. less than 1/40). Figures 10(b) to 10(e) show that the concentrations due to DIN fluxes passing through the major entrances to the inner PRE, namely Hu-men, Jiao-men, Hongqi-men and Heng-men, are about $0 \cdot 5,0.3,0.1$ and $0.2 \mathrm{mg} / 1$ respectively. These high contributions are thought to be related to the high DIN loads shown in Figure 3. However, for Medao-men (Figure 10(f)), the SSR concentration in the PRE is lower than $0.1 \mathrm{mg} / 1$, even though its DIN load is relatively large (see Figure 3). This is because this entrance is located near the outer sea. With the lower DIN loads being located near the outer sea, the contributions from Jiti-men, Hutiao-men and Ya-men to the DIN contribution in the PRE are smaller than that of Medao-men.

\subsection{Prediction for pollution reduction}

One of the main purposes of this study was to provide information to the local environmental protection agency to aid the development of effective water management measures. DIN was chosen as a main indicator owing to its high concentration in the PRE. Figures 11(a) and 11(d) show the present water quality distribution, from which it can be seen that the water quality in the whole of the PRE and some adjacent areas belongs to WQL 5 (i.e. the worst polluted; see Table 2).

The SSR distributions of all pollution loads (Section 5.2) were 


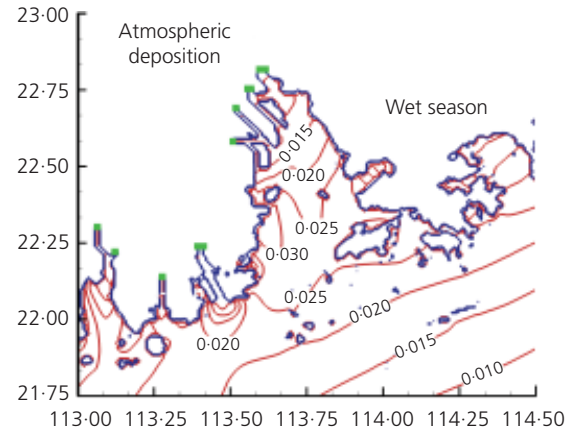

(a)

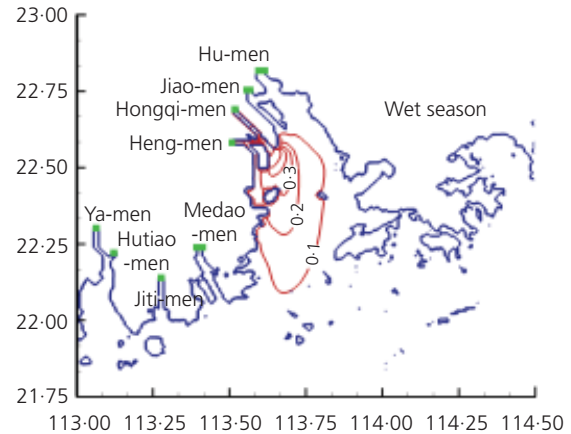

(d)

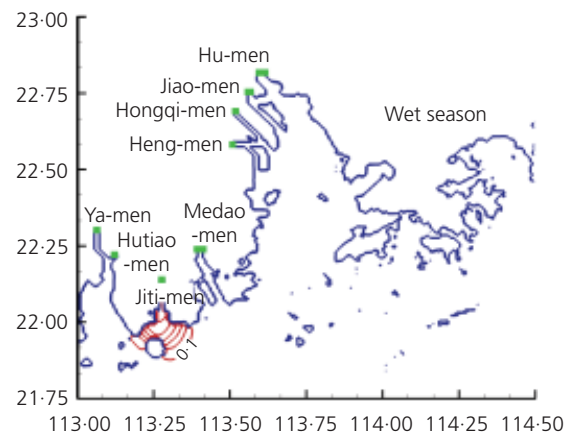

(g)

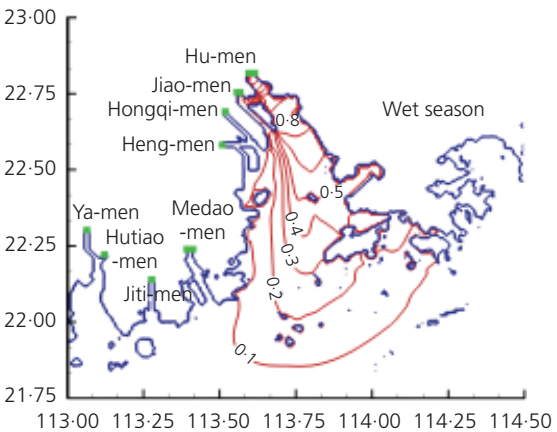

(b)

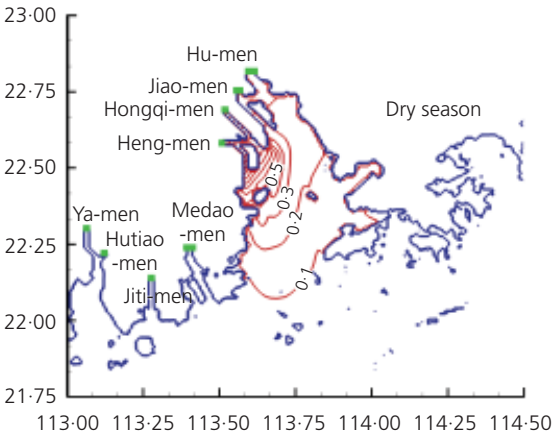

(e)

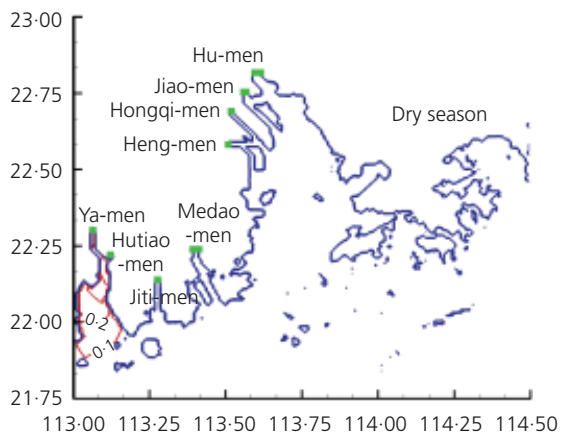

(h)

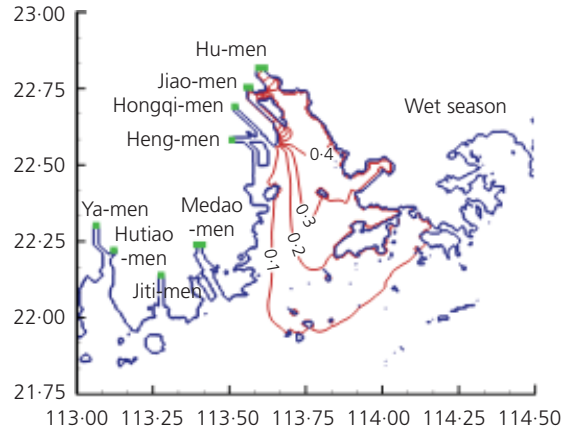

(c)

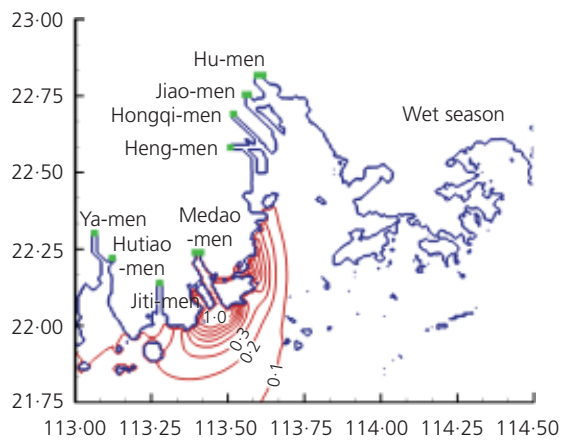

(f)

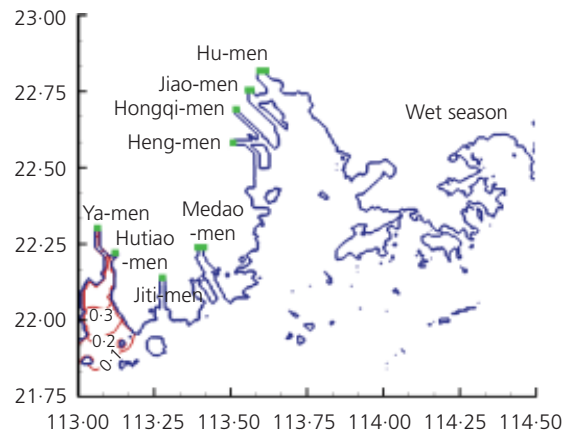

(i)

Figure 10. Contributions of atmospheric deposition (a) and riverine inputs $((b)-(f))$ to dissolved inorganic nitrogen concentration (mg/l) in the Pearl River estuary

used to determine the environmental capacity and optimal special layout of DIN flux with an optimisation method in which the present socio-economic status was taken into account. With this optimal layout, the total DIN load needs to be reduced by $66 \%$ in order to enable all areas of the PRE, with various functions specified by government, to reach present water quality standards. The model predictions for this ideal scenario with the allowable load are shown in Figures 11(b) and 11(e), in which most areas, except the local area in the northern PRE, would reach WQL 1 or WQL 2. However, even assuming that all existing planned reduction measures for DIN were implemented in the relevant catchments for the next 18 years (until 2030), the maximum DIN load reduction is only about $35 \%$ - about half the required reduction. In this scenario with the planned DIN load, most areas in the PRE would still remain in the worst condition of WQL 5 (see Figures 11(c) and 11(f)) even though the polluted area would decrease significantly in comparison with the present status (Figures 11(a) and (d)). Further DIN reduction measures are thus needed.

\section{Conclusion}

Based on data from field surveys, a numerical water quality model has been used to investigate the distributions and seasonal variations of DIN and COD concentrations in the PRE and adjacent coastal areas. The model predictions generally agree well with the field data obtained from the present and previous studies.

Sensitivity analysis showed that the decay coefficient of COD is found to be in the region of $0 \cdot 05-0 \cdot 10 /$ day. For DIN, the decay coefficient is sufficiently small that it can be regarded as a conservative matter in this hydrodynamic environment - it is 


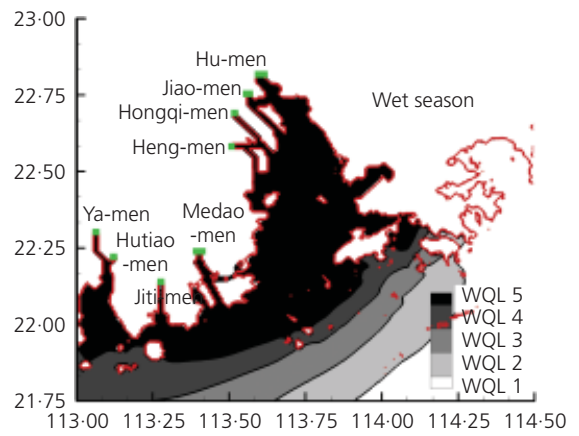

(a)

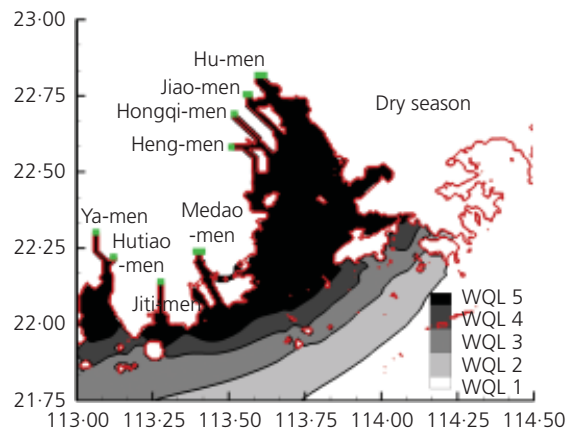

(d)

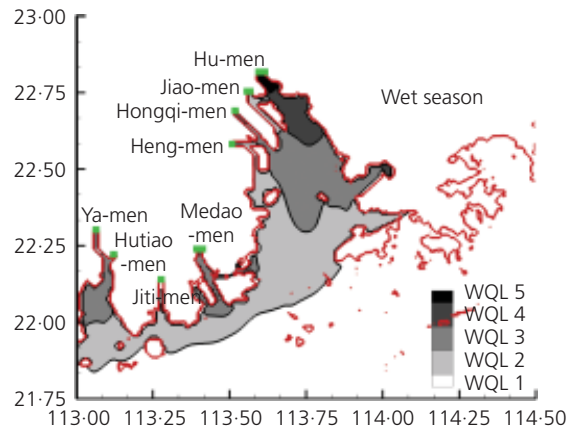

(b)

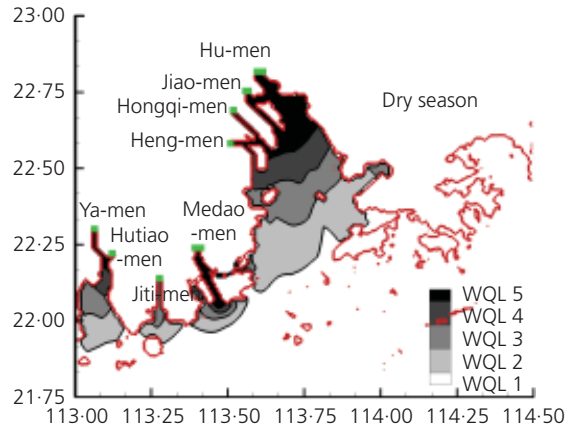

(e)

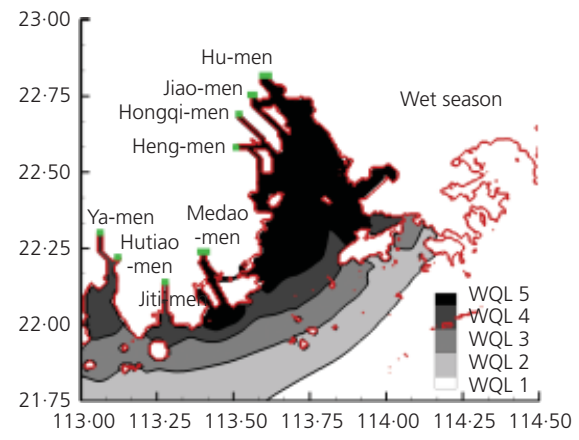

(c)

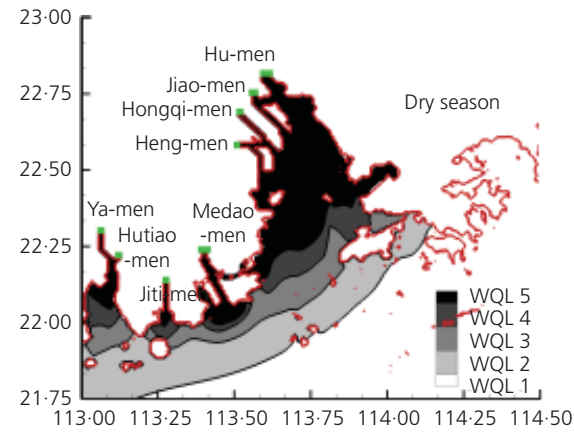

(f)

Figure 11. Model-predicted water quality distribution due to dissolved inorganic nitrogen in scenarios with the present load ((a) and (d)), allowable load ((b) and (e)) and planned load ((c) and (f)). WQL, water quality level

\begin{tabular}{cccccc}
\hline & WQL 1 & WQL 2 & WQL 3 & WQL 4 & WQL 5 \\
\hline DIN: mg/l & $<0.2$ & $>0.2,<0.3$ & $>0.3,<0.4$ & $>0.4,<0.5$ & $>0.5$
\end{tabular}

Table 2. Water quality level (WQL) according to DIN concentration

likely to be flushed out by the discharge before it decays substantially.

The contribution of each major source was predicted using the water quality model. It was shown that the high DIN concentration in the PRE (about $1.2 \mathrm{mg} / \mathrm{l}$ ) is mainly caused by DIN loads passing through four major entrances to the inner PRE: the concentrations attributed to Hu-men, Jiao-men, Hongqi-men and Heng-men are about $0 \cdot 5,0 \cdot 3,0 \cdot 1$ and $0.2 \mathrm{mg} / 1$ respectively. The other four major entrances located in the outer sea area contribute less to the high DIN concentration in the PRE, even though the DIN load from Medao-men is large. The contribution from atmospheric deposition is also at a very low level, with the maximum value being about $0.030 \mathrm{mg} / \mathrm{l}$.

According to the Chinese seawater quality standard, the present status of the whole of the PRE and some adjacent areas is WQL 5 - the worst polluted water. Model predictions show that a
$66 \%$ DIN load reduction is required in order to enable all functional areas in the PRE to reach the required water quality standards. Taking all of the planned DIN load reduction measures into account in the catchment until 2030 would result in a $35 \%$ DIN load reduction ratio, and water quality in most areas in the PRE would still be WQL 5. Further plans for reduction are therefore required.

\section{Acknowledgements}

This research was financially supported by the National Natural Science Foundation of China (11002099), the Blue Sea Action Plan in Pearl River Estuary and Adjacent Sea Areas (HBZX200607), and the Tsinghua University Research Fund (20111081128).

\section{REFERENCES}

Cai WJ, Dai MH, Wang YC et al. (2004) The biogeochemistry of inorganic carbon and nutrients in the Pearl River estuary and 
the adjacent Northern South China Sea. Continental Shelf

Research 24(12): 1201-1319.

Chau KW and Jiang YW (2002) Three-dimensional pollutant transport model for the Pearl River Estuary. Water Research 36(8): 2029-2039.

Chau KW and Jiang YW (2003) Simulation of transboundary pollutant transport action in the Pearl River delta.

Chemosphere 52(9): 1615-1621.

Chen CQ, Tang SL, Pan ZL and Haigang Z (2007) Remotely sensed assessment of water quality levels in the Pearl River Estuary, China. Marine Pollution Bulletin 54(8): 1264-1272.

Dagg MJ and Breed GA (2003) Biological effects of Mississippi River nitrogen on the northern Gulf of Mexico - a review and synthesis. Journal of Marine System 43(3-4): 133-152.

Dai M, Guo X, Zhai W et al. (2006) Oxygen depletion in the upper reach of the Pearl River estuary during a winter drought. Marine Chemistry 102(1-2): 159-169.

Dong LX, Su JL, Wong LA et al. (2004) Seasonal variation and dynamics of Pearl River Plume. Continental Shelf Research 24(16): $1761-1777$.

Egbert GD and Erofeeva SY (2002) Efficient inverse modeling of barotropic ocean tides. Journal of Atmospheric and Oceanic Technology 19(2): 183-204.

Fan ML, Wang XM, Wang Q et al. (2010) Atmospheric deposition of nitrogen and phosphorus into the Hengmen of Pearl River Estuary. Journal of Tropical Oceanography 29(1) 51-56 (in Chinese).

Guan WB, Wong LA and Xu DF (2001) Modeling nitrogen and phosphorus cycles and dissolved oxygen in the Zhujiang River Estuary, Part I. Model Development. Acta Oceanologica Sinica 20(4): 493-504.

Harrison PJ, Yin K, Gan JP et al. (2008) Physical-biological coupling in the Pearl River Estuary. Continental Shelf Research 28(12): 1405-1415.

He XC, Huang Y and Zhang J (2008) Estimation of discharge from pollution source in Pearl River Estuary and surrounding sea area and pollution source assessment study. Pearl River 2: 14-17 (in Chinese).

HoN (Hydrographer of the Navy) (1990) Admiralty Tidal Tables and Tidal Stream Tables. HoN, London, UK.

Hou WD, Chen XH, Jiang T and Tu XJ (2004) Temporal change of flow distribution in river network of the delta of West River and North River. Acta Scientiarum Naturalium Universitatis Sunyatseni 43: 204-207 (in Chinese).

Huang XP, Huang LM and Yue WZ (2003) The characteristics of nutrients and eutrophication in the Pearl River estuary, South China. Marine Pollution Bulletin 47(1-6): 30-36.

Kot SC and Hu SL (1995) Water Flows and Sediment Transport in Pearl River Estuary and Wave in South China Sea near Hong Kong. Coastal Infrastructure Development in Hong Kong - A Review. Hong Kong Government, Hong Kong.

Lin B and Falconer RA (1995) Modelling sediment fluxes in estuarine waters using a curvilinear co-ordinate grid system, estuarine. Coastal and Shelf Science 41(1): 413-428.

Lohrenz SE, Dagg MJ and Whitledge TE (1990) Enhanced primary production at the plume/oceanic interface of the Mississippi River. Continental Shelf Research 10(7): 639-664.

Mao QW, Shi P, Yin K et al. (2004) Tides and tidal currents in the Pearl River Estuary. Continental Shelf Research 24(16): 1797-1808.

Nie HT and Tao JH (2009a) Inversion of dispersion coefficient in water quality model using optimal perturbation algorithm. Applied Mathematics and Mechanics 30(6): 703-712.

Nie HT and Tao JH (2009b) Eco-environmental status of the Bohai Bay and the impact of coastal exploitation. Marine Science Bulletin 11(2): 81-95.

Nielsen P (2009) Coastal and Estuarine Processes. World Scientific, Singapore.

PRWRC (Pearl River Water Resources Committee) (1991) The Zhujiang (Pearl River) Archive, vol. 1. Guangdong Science and Technology Press, Guangzhou, China (in Chinese).

Qiu DJ, Huang LM, Zhang JL and Lin SJ (2010) Phytoplankton dynamics in and near the highly eutrophic Pearl River Estuary, South China Sea. Continental Shelf Research 30(2): 177-186.

Rabouille C, Conley DJ, Dai MH et al. (2008) Comparison of hypoxia among four river-dominated ocean margins: The Changjiang (Yangtze), Mississippi, Pearl and Rhone rivers. Continental Shelf Research 28(12): 1527-1537.

Sun J and Tao JH (2006) Relation matrix of water exchange for sea bays and its application. China Ocean Engineering 20(4): 529-544.

Sun J and Tao JH (2010) A new wetting and drying method for moving boundary in shallow water flow models. China Ocean Engineering 24(1): 79-92.

Sun J, Nie HT, Tao JH and Fu G (2009) Analysis of the pulse impact on sea area by the sluice-controlled river. Proceedings of International Conference of GEF (Global Environment Facility) Hai Basin Integrated Water Resources and Environment Management, River Basin Research and Planning Approach, Beijing, China, pp. 71-77.

Tao JH, Li QX, Falconer RA et al. (2001) Modelling and assessment of water quality in a semi-enclosed shallow bay. Journal of Hydraulic Research 39(6): 611-617.

Wang ZL, Tao JH, Ji M et al. (2004) Study on dispersion and degradation of COD in the Bohai Bay. Marine Science Bulletin 23(1): 27-31 (in Chinese).

Wong LA, Chen JC, Xue H et al. (2003) A model study of the circulation in the Pearl River Estuary and its adjacent coastal waters: 1. Simulation and comparison with observations. Journal of Geophysical Research 108(C5): 3156, http:// dx.doi.org/doi:10.1029/2002JC001451.

Xu J, Ho AYT, Yin K et al. (2008) Temporal and spatial variation in nutrient stoichiometry and regulation of phytoplankton biomass in Hong Kong waters: influence of the Pearl River outflow and sewage inputs. Marine Pollution Bulletin 57(6-12): 335-348.

Yin K and Harrison PJ (2008) Nitrogen over enrichment in 
subtropical Pearl River estuarine coastal waters: possible causes and consequences. Continental Shelf Research 28(12): $1435-1442$.

Yin K, Qian PY, Chen JC et al. (2000) Dynamic of nutrients and phytoplankton biomass in the Pearl River estuary and adjacent waters of Hong Kong during summer: preliminary evidence for phosphorus and silicon limitation. Marine Ecology Progress Series 194: 295-305.

Zhang J, Yu ZG, Wang JT et al. (1999) The subtropical Zhujiang
(Pearl River) Estuary: nutrient, trace species and the relationship to photosynthesis. Estuarine, Coastal and Shelf Science 49(3): 385-400.

Zhang S, Lu XX, Higgitt DL et al. (2008) Recent change of water discharge and sediment load in the Zhujiang (Pearl River) Basin, China. Global and Planetary Change 60(3-4): 365-380.

Zhao H (ed.) (1990) The Evolution of the Pearl River Estuary. China Ocean Press, Beijing, China (in Chinese)

\section{WHAT DO YOU THINK?}

To discuss this paper, please email up to 500 words to the editor at journals@ice.org.uk. Your contribution will be forwarded to the author(s) for a reply and, if considered appropriate by the editorial panel, will be published as a discussion in a future issue of the journal.

Proceedings journals rely entirely on contributions sent in by civil engineering professionals, academics and students. Papers should be 2000-5000 words long (briefing papers should be 1000-2000 words long), with adequate illustrations and references. You can submit your paper online via www.icevirtuallibrary.com/content/journals, where you will also find detailed author guidelines. 